\title{
Roles of Cerebellum and Basal Ganglia in Initiation and Control of Movements
}

\author{
V. B. BROOKS
}

SUMMARY: Theories of function of the cerebellum and basal ganglia are examined in the light of recent experimental findings obtained with the local cooling method, and both are matched against clinical observations. Evidence is summarized for a programming and initiating role in monkeys' elbow movements of the lateral, and to a lesser degree, intermediate, cerebellum. Cooling either nuclei affected movements, but neither seemed to be important for precentral cortical unit discharge accompanying compensation for suddenly applied load pulses. The globus pallidus seemed to be importantly involved in movement guidance in the absence of vision.

RÉSUMÉ: A la lumière d'études expérimentales récentes obtenues par la méthode de refroidissement local, les théories concernant la fonction du cervelet et des ganglions de la base furent étudiées et furent appuyées par des observations cliniques. Nous résumons les faits montrant que les noyaux latéraux et, à un degré moindre, intermédiaires du cervelet jouent un rôle de programmation et d'initiation dans les mouvements du coude chez le singe. Le refroidissement de l'un ou de l'autre de ces noyaux affecte les mouvements mais ne semble pas important concernant les décharges unitaires corticales précentrales accompagnant la compensation à la suite de charges appliquées soulainement. En absence de vision, le globus pallidus semble avoir un rôle très important dans le contrôle du mouvement.

From the Department of Physiology, University of Western Ontario, London, Ontario, Canada N6A 5 C1.

Reprint requests to Dr. V. B. Brooks, Department of Physiology, University of Western Ontario, London, Ontario, Canada N6A 5C1.

Supported in part by the Medical Research Council of Canada (MT-4465) and the National Institutes of Health, US PHS (NS-10311).

\section{INTRODUCTION}

\section{Initiation}

Cerebellar involvement in initiation of voluntary movement was first clearly demonstrated by Holmes (1917) who measured delays of 100-200 msec in arm flexions of patients with one-sided lesions of the lateral lobe. We are indebted to Evarts and Thach (1969) in reviving interest in this aspect of cerebellar function, which they related to its anatomical connections. The neocerebellum receives most of its afferent input from association areas of the cerebral cortex by way of the pons and the inferior olive, while sending most of its efferent dentate output to the motor cortex by way of the ventroanterior and ventrolateral nuclei (VA/VL) of the thalamus.

Anatomical convergence from association cortex through the basal ganglia and cerebellum, via the thalamic funnel of VL, to the motor cortex was stressed by Kemp and Powell (1971). Figure 1 reproduces their diagram emphasizing the analogy of this aspect of the two systems. The suggestion that these pathways play a role in planning and initiating movements is strengthened by the lack of spinal inputs to the lateral cerebellum (cf. Brodal, 1969; Dow and Moruzzi, 1951) and the relative lack to the basal ganglia, except for some from the thalamus (Powell and Cowan, 1956). At movement onset, some dentate neurons, but by no means all, tend to discharge before pyramidal tract neurons and may therefore give instructions for initiation to the cortex (Thach, 1975). This route through the lateral cerebellum is currently thought to be concerned primarily with the flow of programs for the motor cortex. Eccles (1969, 1973) and Ito (1970) have proposed that the channels for the neural traffic from the "will" to actual movement inception run from the cerebral association cortex to the motor cortex with a detour for learning through the cerebellum. Figure 2 is a diagram for this sequence, modified from the review by Allen and Tsukahara (1974). The interrupted lines (labelled A and B) refer to our method, to be described below. The scheme is based on the functional anatomy of the cerebellum.

Figure 3 combines diagrams from Eccles charting his view (1969) of the cerebellar connections and their participation in the evolving movement. The labels Cool and Record are inserted with reference to our method, described in a later section. The suggestion is that muscle choice and movement parameters would become "programmed" in the cerebellum with learning, to fashion the motor commands that issue from the motor cortex. Various movement parameters may be programmed (cf. Brooks, 1974) such as force (cf. Evarts, 1975), direction (Schmidt et al., 1975) or duration (Conrad and Brooks, 1974). Performance skill would be improved by cerebellar action because speed and coordination would become independent of feedback from the periphery to the cerebrum and cerebellum, that may consume as much as $100 \mathrm{msec}$, while central loop time from the cortex through the cerebellum back to the motor cortex is only $10-20 \mathrm{msec}$ (Eccles, 1972, 1973). This timing of neural traffic along paths outlined in Figure 3 is plotted in Figure 4 taken from Allen and Tsukahara (1974). The view of the lateral cerebellum as a programmer fits the clinical obser- 


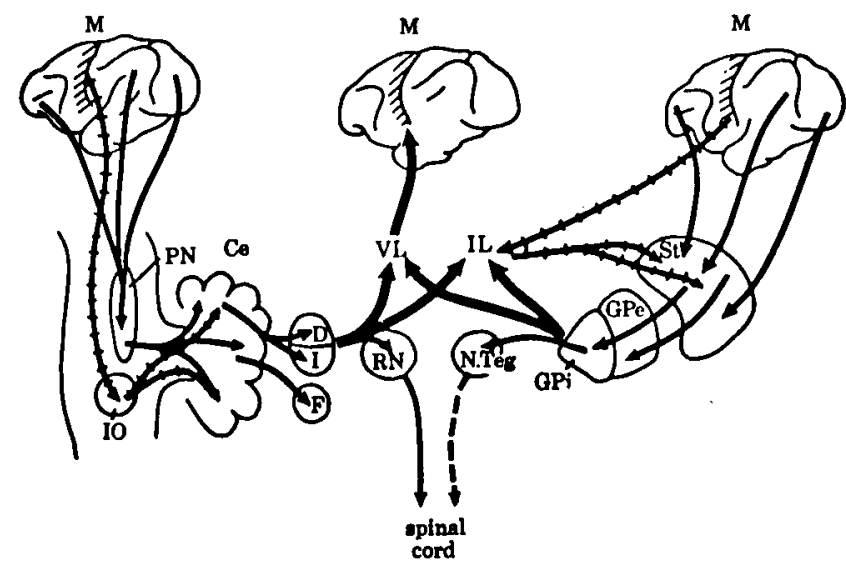

Figure I-Diagram of anatomical connections stressing similarities of cerebral links with the cerebellum and basal ganglia. Interrupted arrow indicates possible connection. Ce, cerebellar cortex; D, dentate nucleus; F, fastigial nucleus; GPe, globus pallidus, external segment; GPi, globus pallidus, internal segment; I, interpositus nucleus; IL, intralaminar nuclei of the thalamus; 10 , inferior olive; $M$, motor cortex; N.Teg, tegmental nuclei; PN, pontine nuclei; RN, red nuc-

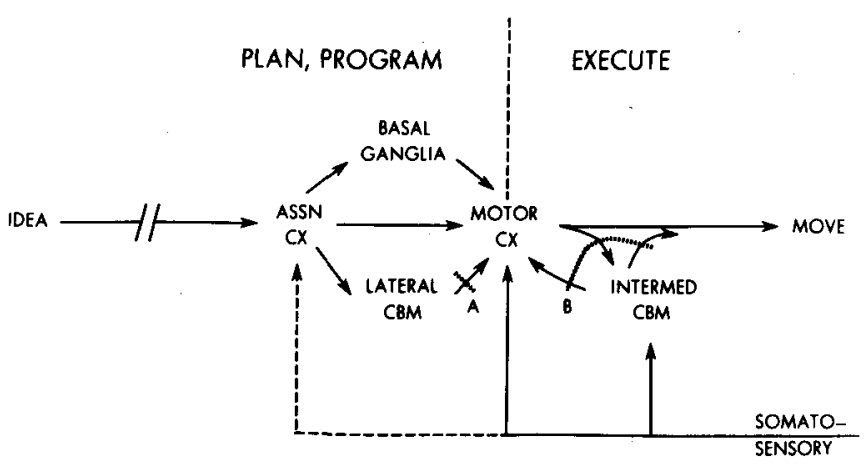

Figure 2-Diagram of possible functional connections, stressing possible roles of cerebrum (CX), cerebellum (CBM), and basal ganglia. Interrupted arrow indicates possible connection. Heavy dashed lines labelled $A$ and $B$ refer to our experiments as explained in text.

(Modified from Allen and Tsukahara, 1974.)

leus; St, Striatum; VL, ventro-lateral nucleus of the thalamus.

(From Kemp and Powell, 1971.) vation of decomposition of complex movements as well as slowing of simple movements (Holmes, 1917). It does not exclude a role for the cerebellum as initiator of movements. Evidence on relative timing of neurons in the dentate and the motor cortex (Thach, 1975) and in the VL (cf. Evarts, 1975) suggests that these structures are not the only gates to the motor cortex; the cortico-cortical connections from the association cortex drawn in Figure 2 may also be important (cf. Pandya and Kuypers, 1969).

Parkinsonian, as opposed to cerebellar patients, do not have prolonged reaction times except in tasks that depend on making a choice between actions (Butz et al., 1970). Yet, Parkinsonian patients have difficulties in initiating slow movements (cf. Denny-Brown, 1962; Martin, 1967), which has been associated with impaired nigrostriatal influence by the dopaminergic substantia nigra (Dahlstrom and Fuxe, 1964; Poirier and Sourkes, 1965; and cf. Carpenter, 1973). (The noradrenergic reticular disinhibition of cerebellar nuclei from the locus ceruleus (Ungerstedt, 1971; Garver and Sladek, 1975) may be analogous, but it is not known whether it is essential for movement initiation.) Consideration of Figurel would lead to the expecta- tion that neurons in the basal ganglia would also be related to limb movements, and some of them might discharge before initiation. This was found to be so for the putamen and the globus pallidus by DeLong and Strick (1974). The projection to the motor cortex from the basal ganglia by way of the globus pallidus through VA/VL cannot be the only output of importance however, because lesions in VL produce neither akinesia nor rigidity (cf. Cooper, 1969). Perhaps a possible descending pallido-spinal projection through the tegmental nuclei (Fig. 1) is also concerned there. J. Purdon Martin (1967) has described how akinesic patients could walk when given visual cues, such as white lines on the ground spaced roughly one step from another. This suggests that inadequate or inactive programs were bypassed or reactivated by additional information, that could reprogram the motor cortex independently of the basal ganglia.

\section{Control}

Regulatory control of movement execution by the cerebellum and the basal ganglia have been well described. Holmes (1917) defined the deficiencies in cerebellar patients with single-sided, lateral, lesions as errors of rate, force, tone, direction, coordination and regularity, as well as the appearance of tremor during effort. These signs were thought to arise from improper function of sense organs from "deeper structures" following Sherrington's concept of the cerebellum as "the head ganglion of the proprioceptive system." Holmes (1917) ". . . emphasized that the control of movements by vision has no influence on their accuracy, and that they are quite as 'ataxic' when the patient's eyes are open as when they are closed."

Granit et al (1955) identified reduction of muscle spindle responses to muscle stretch after lesions of the anterior lobe, a reduction that was then shown to have been caused by depressed fusimotor drive (Gilman and Ebel, 1970). Granit (1970) takes the view that the cerebellum is ordinarily needed to keep up the supportive alpha-gamma-linkage that provides correct timing and intensity of muscle tension. The view of the cerebellum as giving continuous correction of the evolving limb movements was developed by Eccles (1969) and subsequently by Allen and Tsukahara (1974) who stressed that information from the fastigial and the interpositus nuclei reached the motor cortex in sufficient time to adjust ongoing actions as well as to 

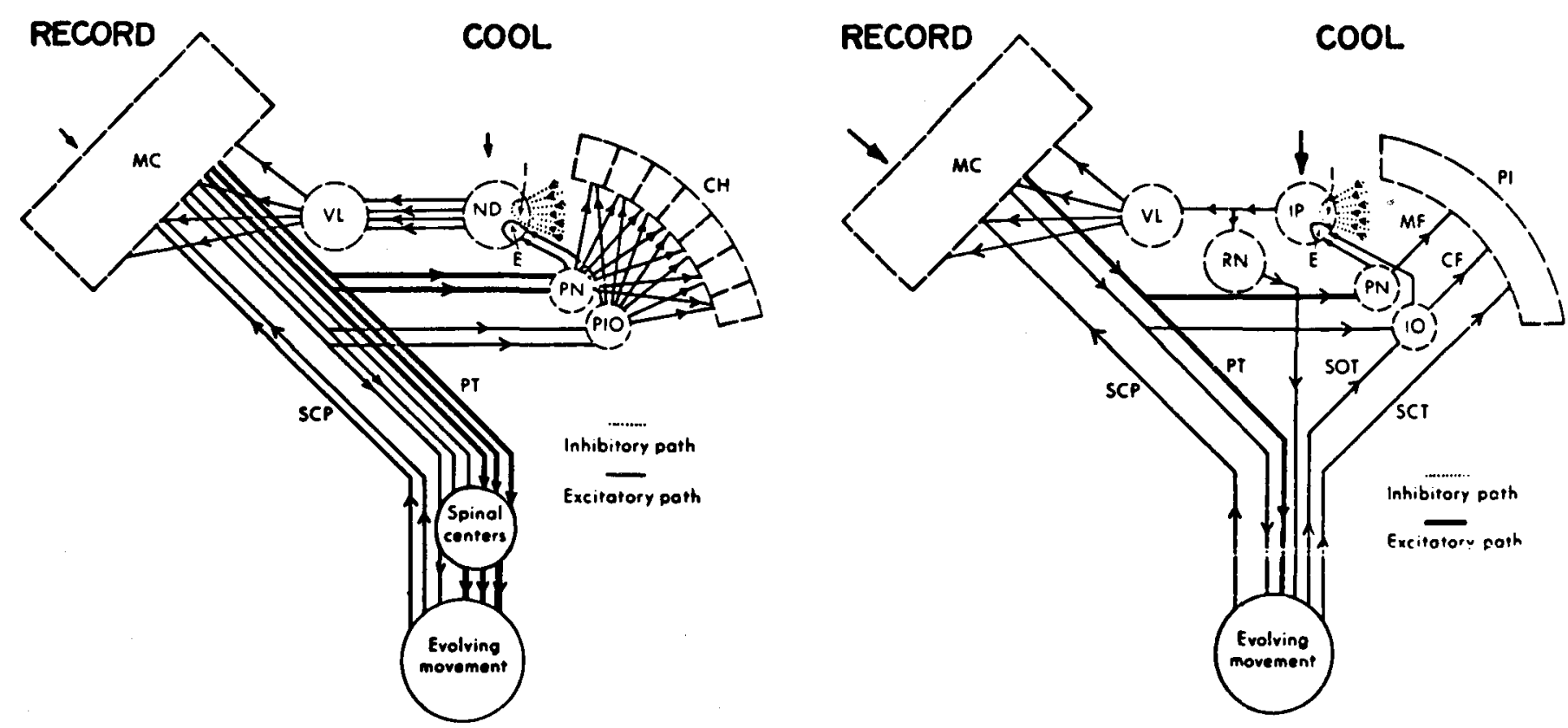

Figure 3-Diagrams of functional connections of the motor cortex (MC), evolving movement and on the left: cerebellar hemispheres (CH) and on the right; pars intermedia (PI). Labels "COOL" and "RECORD" refer to our experiments as explained in text. E and I symbolize excitatory and inhibitory synapses; PT, pyramidal tract; SCP, spinocortical pathways; ND, nucleus dentatus or lateralis; VL, ventrolateral nucleus of the thalamus; PN, pontine nuclei; PIO, principal inferior olive; IP, nucleus interpositus; RN, red nucleus.

(Modified from Eccles, 1969.)

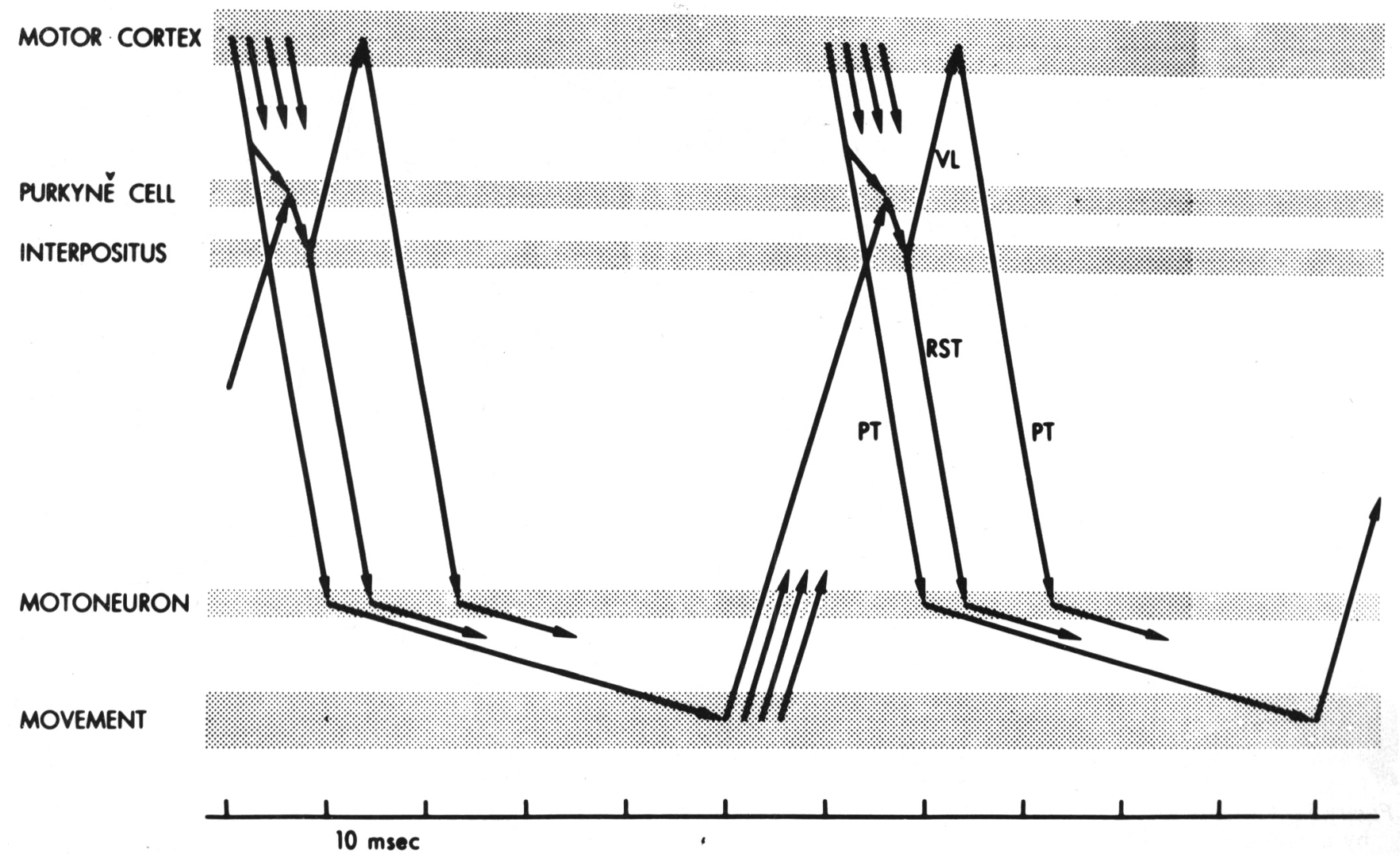

Figure 4-Diagram of timing signals in the connections of Fig. 3B. PT, pyramidal tract; RST, rubrospinal tract; VL, ventral lateral nucleus of the thalamus.

(From Allen and Tsukahara, 1974.) 
prepare the cortex for impending limb movements (cf. Fig. 4). The latter point differs from the line taken by Holmes (1917) who surmised that "The cerebellum might be therefore regarded as a motor reinforcing

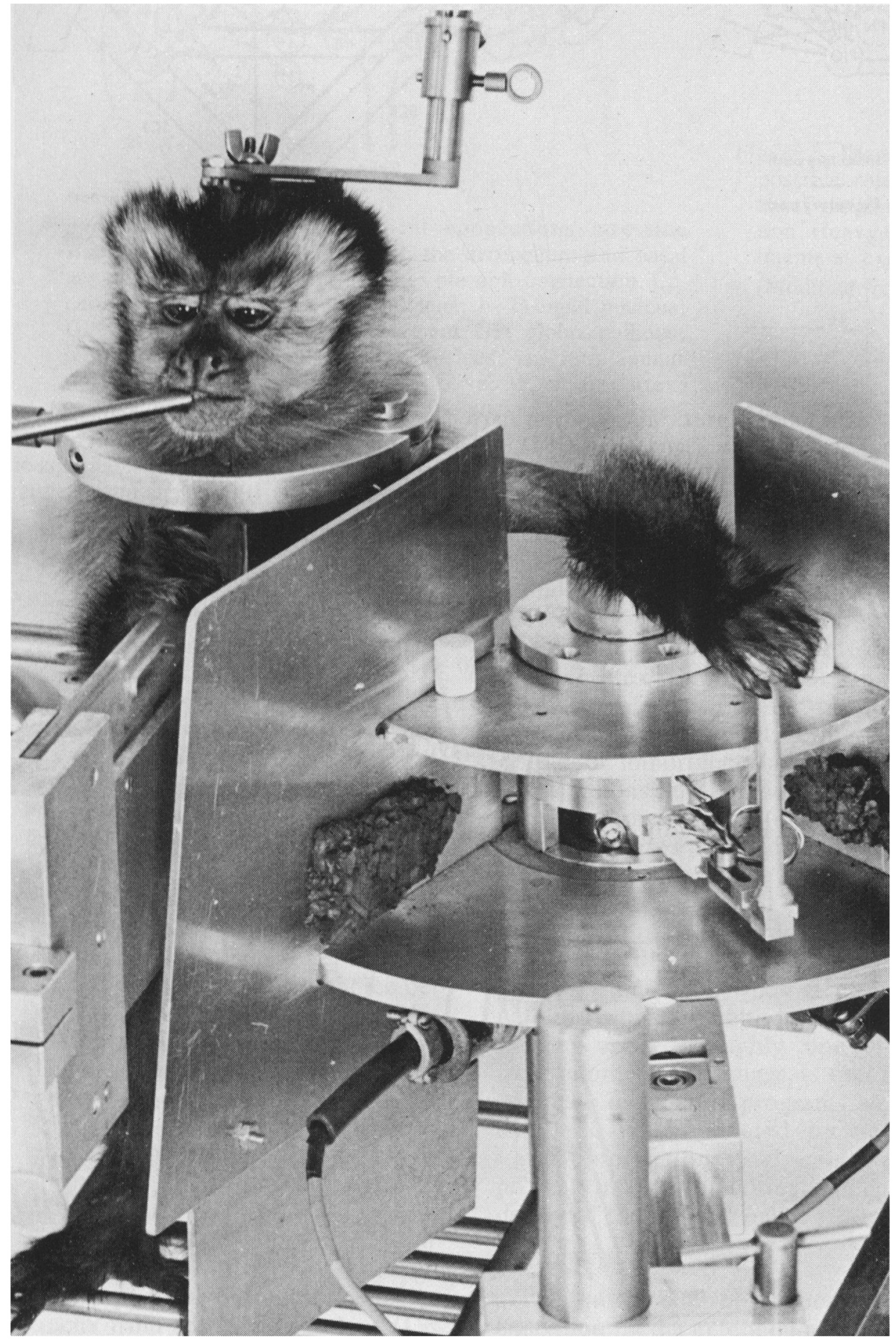

Figure 5-A Cebus monkey in the task situation. The animal is restrained in the chair by a neck collar and head holder. A juice reward delivery tube is in front of the mouth. The left elbow rests on a rotatable pivot, and the hand grasps the knob of the handle, which is connected to a potentiometer and torque motor. Not shown are opaque plate that blocks monkey's view of his arm, and the microdrive for recording in motor cortex. organ, in the sense in which Luciani and others have used this term. It seems, however, probable that it takes no direct part in the processes, whether initiated reflexly or voluntarily, that produce motor ef-

fects, and that it does not augment these, but that it 'sets' or 'tunes', or regulates the activity of certain motor mechanisms, most probably spinal, so that the response to a volitional stimulus is immediate, effective and proportional to the intensity of the cerebral impulse."

The pars intermedia that receives spinocerebellar inputs and has its outflow through $n$. interpositus, is illustrated in Figures 1 and 3 (cf. Eccles, 1969). The corrective information forwarded to the motor cortex describes well-localized details of proprioceptive, kinesthetic, and somesthetic events, as well as the progress of movements as sensed by interneurons with convergent input (cf. Oscarsson, 1973). This corresponds to the sensory input measurable in the motor cortex, as reviewed by Brooks and Stoney (1971). Those authors also reviewed the input/output evidence for the possibility that force, speed, and displacement may be controlled separately by neurons in the motor cortex, for which a theoretical base has been suggested by Houk (1972), and peripheral input possibilities have been considered by Stein (1974). The possibility exists, however, that derived functions of these parameters are controlled, such as the length/tension relationship of muscle, i.e. its stiffness (Nichols and Houk, 1973). N. interpositus can presumably adjust movements not only through its cortical outflow, but also through its descending outflow by way of the magnocellular part of the red nucleus, whose spinal projection and function in monkey parallels the corticospinal one, except for fine control of the fingers (Lawrence and Kuypers, 1968a, b).

Ataxia and tremor do not necessarily depend on peripheral input, however. Liu and Chambers (1971) demonstrated that nuclear lesions of dentate and interpositus made before or after deafferentation of one or both forelimbs added their own typical dysfunctions to those produced by deafferentation alone. They describe, that in the ensuing months ". . . the ipsilateral cerebellar deafferented arm also showed the same general pattern of recovery as 

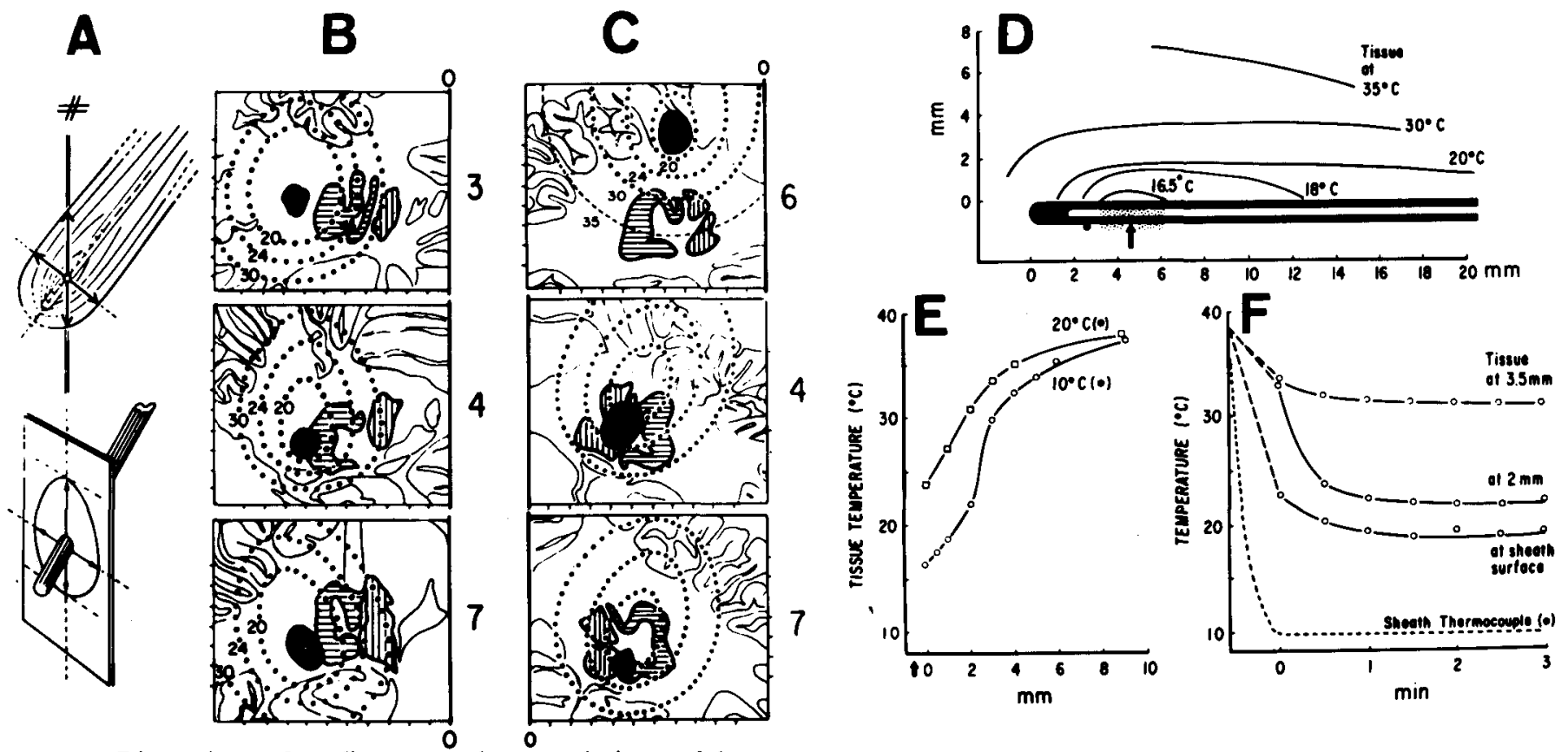

Figure 6-Dimensions of cooling as used presently in our laboratory.

A: Drawing of cooling probe sheath with surrounding isotherms, and below the resulting projection onto a frontal brain section.

B: Drawings of frontal sections taken midway through the cerebellar nuclei from 3 monkeys. Estimated isotherms for $20^{\circ} \mathrm{C}, 24^{\circ} \mathrm{C}$, and $30^{\circ}$ drawn as dotted lines, for probe ref. temp. of $10^{\circ} \mathrm{C}$. Dentate is hatched horizontally, and IP vertically. Midline at right border $(\mathrm{O})$ of drawings that are marked in $\mathrm{mm}$ at bottom.

$\mathrm{C}$ : As in $\mathrm{B}$, but for more medial penetrations.

D: Details of isotherms measured in tissue, for probe ref. temp. of $10^{\circ} \mathrm{C}$. Coldest region at arrow.

E: Tissue temperatures at various distances from coldest region for probe ref. temps. of $20^{\circ} \mathrm{C}$ and $10^{\circ} \mathrm{C}$.

F: Tissue temperatures at various times after probe ref. temp. reached $10^{\circ} \mathrm{C}$ at 0 time.

(Modified from Brooks et al., 1973, and Uno et al., 1973.)

the simple deafferented arm, but it was much slower and was wildly ataxic and poorly coordinated, especially at the distal joints . . .". At the same time there was no detectable loss of recognition of learned goal position, even when vision of the task area was blocked. They concluded ". . . that the primary deficit in the cerebellar deafferent arm is due to a failure to start and stop movements with the proper timing, resulting in an overshoot. This overshoot with a preservation of a position end point and an attempt to correct for the error produces the ataxic tremor ....". Similarly Gilman (1972) reported that dysmetria and tremor consequent to deafferentation worsened significantly after cerebellar ablation, which led him to conclude "... that there are mechanisms important in cerebellar tremor which, though still unidentified, are clearly independent of the fusimotor efferent-spindle afferent circuit ...".
The basal ganglia do not seem to give ongoing corrections like the cerebellum (cf. Fig. 1). They do not receive any equivalent to that splendid array of spino-cerebellar inputs whose intricate patterns of termination in cerebellar cortex suggested its computer function (cf. Eccles, 1973). The intralaminar thalamic nuclei inputs to the basal ganglia may give progress reports about movements, rather than detailed status reports about particular peripheral events, since their peripheral receptive fields are convergent (cf. Bowsher, 1965). Clinical evidence marshalled by J. Purdon Martin (1967) implicates loss of postural reflexes, quite apart from increased co-contraction of antagonistic muscles, tremor at rest, hypokinesia, or certain instances of hyperkinesia.

\section{METHODS}

We have concentrated our studies on properties of elbow movements made by monkeys that were trained to turn a handle in a horizontal arc between two target areas. Figure 5 shows a Cebus monkey in the experimental situation with the arm on the handle, and a feeding tube in front of his mouth to provide a juice reward for correct performance. The animal's view of the moving arm was blocked during experiments by an opaque plate (not shown in Figure 5) to make the movements dependent on training and to restrict feedback to proprioceptive, kinesthetic, and somesthetic information. Performance of the animals was measured from records of handle displacement, relevant EMG's, and in some instances by unit recording from the motor cortex (indicated in Figure 3). The head was held steady by a head holder attached to bolts anchored in dental cement attached to the skull, similar to the method developed by Evarts (cf. summary in 1975).

A special additional procedure used in our laboratory was the study of temporary behavioral and 


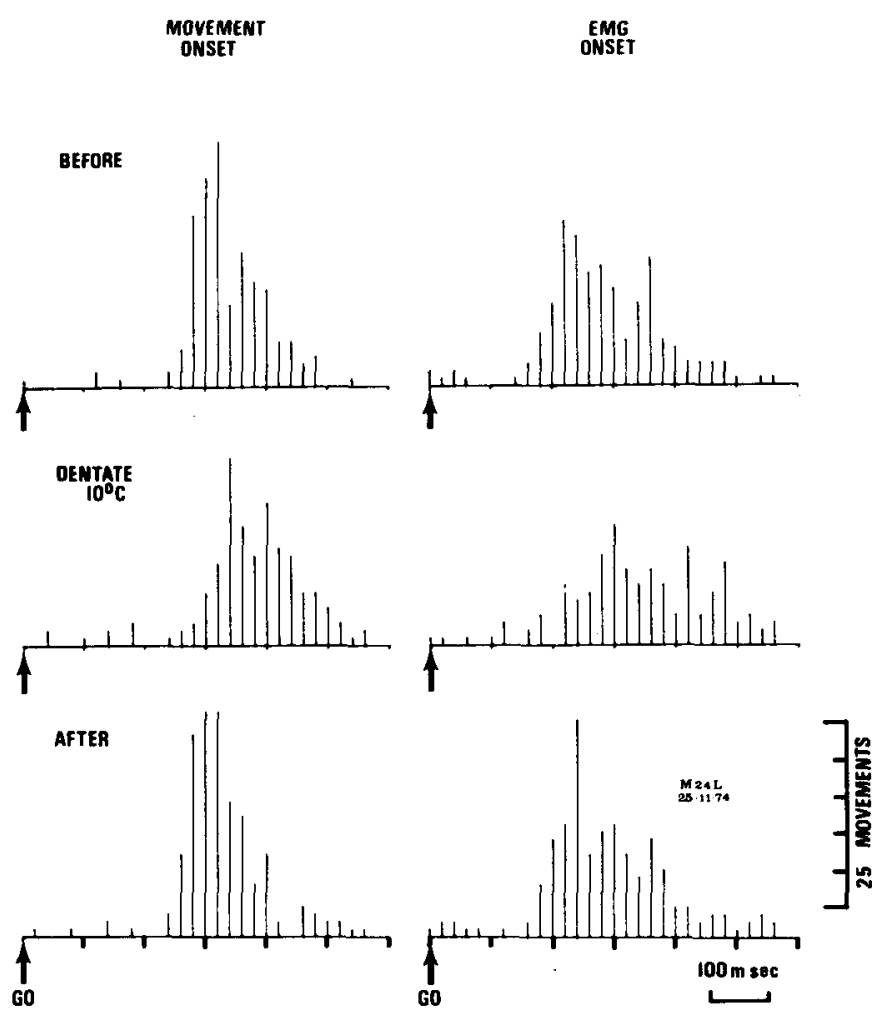

Figure 7-Effects on onset of movements (left column) and EMG (right) of dentate cooling $\left(10^{\circ} \mathrm{C}\right.$ probe ref. temp.). Computer-generated histograms plotted from $20 \mathrm{msec}$ bins, after GO signals marked by arrows at beginning of time bases that show $100 \mathrm{msec}$ timers. Ordinates divided at intervals of 5 movement units.

(From Meyer-Lohmann, Hore and Brooks, unpublished.)

physiological dysfunctions produced by local cooling of neural structures. This was achieved by chronic implantation of cooling probe sheaths into appropriate neural centers, that could then be depressed when a cooling probe was inserted during experimental trials, as indicated in Figures 1 and 3 . Details of the method are described in Brooks et al. (1973). Cooling of tissues down to $15^{\circ} \mathrm{C}$ preferentially blocks synaptic transmission (Jasper et al., 1970; Bénita and Condé, 1972). Impulse conduction in fibers is slowed by a drop of only a few degrees (Andersen et al., 1972), but it is stopped only near $10^{\circ} \mathrm{C}$. Use of cooling chambers attached chronically to the skull above trephine holes was initiated by Trendelenburg (1911) who compared behavioral deficits of monkeys, dogs and cats during cooling of the surface of the motor cortex to the effect of excision. In three pre-

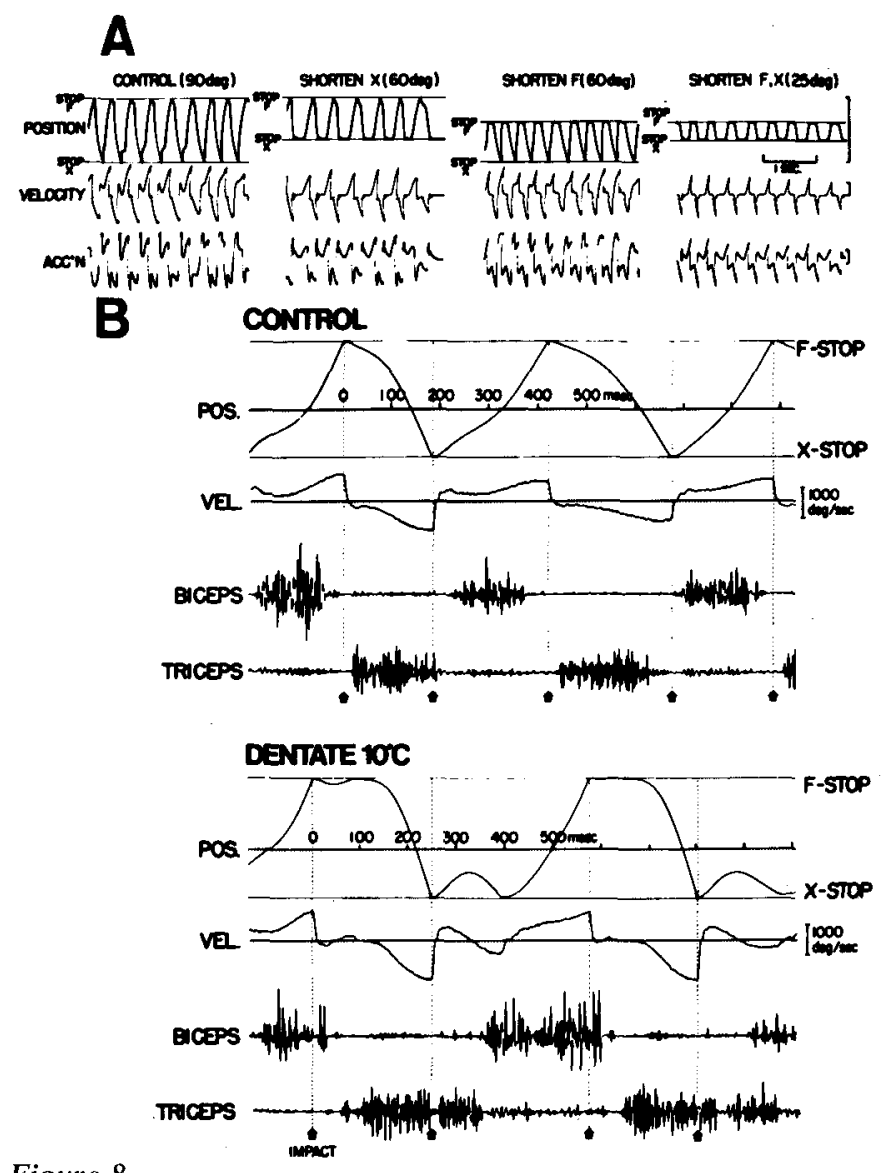

Figure 8-

A: Rapid alternating arm movements made after unexpected changes of movement range. In the $2 \mathrm{nd}, 3 \mathrm{rd}$ and 4 th columns the mechanical stops for extension $(X)$, flexion $(F)$ and both were moved towards the center. Calibrations for position: $90 \mathrm{deg}$; velocity: $500 \mathrm{deg} / \mathrm{sec}$; and for acceleration $5000 \mathrm{deg} / \mathrm{sec}^{2}$.

B: Traces of movement parameters and EMG during control (above) and cooling ipsilateral dentate (below). Vertical broken lines and arrows indicate moments of impact on mechanical stop. Stops are drawn as horizontal lines for the position traces on the flexion (F) and extension (X) sides. All records of individual trials.

(Modified from Conrad and Brooks, 1974.)

ceding papers (Trendelenburg, 1910a, $b$, c) he reviewed the origin of the method from nerve cooling; explained his own rationale, and reported the results of cooling spinal cords of reduced preparations on reflexes. He also reviewed the effects of cooling the floor of the fourth ventricle on respiratory and cardiovascular systems. The effects on limb movements of cooling the cerebellar surface in acutely prepared cats and dogs were first observed over 50 years ago by Camis (1923; also see
Dow and Moruzzi, 1958). The similarity of effects on spindle discharge of cerebellar lesions and of cooling the cat's anterior lobe was shown by Granit et al. (1955). Development of stereotaxis by Ranson in the thirties (recounted by Brobeck, 1974) made it possible to implant probes in selected places. The development of that method during the past decade has been traced by Brooks et al. (1973). Figure 6 illustrates the dimensions in space (A-E) and time (F) of our cooling procedure. 


\section{REVIEW OF SOME RESULTS}

\section{Initiation}

We have found recently (Miller et al., 1975), that movement onset was reversibly delayed by about 100 msec when the dentate ipsilateral to the operant arm was cooled briefly. Figure 7 illustrates these increased reaction times, and equivalent increases for EMG onset, proving that this was a truly delayed initiation and not just a slow build-up of force. Changes in firing of cells in the motor cortex were observed in other trials (Hore et al., 1975) although it was found that for many their normal relation to movement onset was preserved. Delays of initiation by about $100 \mathrm{msec}$ could have been caused by the dis-facilitation of the motor cortex due to inactivation of many dentate neurons. Input from residual dentate neurons as well as from other brain structures would then have to generate more cortical summation which could occur effec- tively in that time (cf. Purpura, 1972).

What should one expect in similar experiments with cooling $n$. interpositus (IP), whose major output goes to the brainstem as well as to the cortex (cf. Figures 1 and 3)? We observed lesser delays of EMG and movement initiation, but as with the dentate, they were coupled to delays in changes of neural firing. The histology of these animals is not available yet. If cooling was restricted to the IP, and did not spread to the dentate, then the route of the IP in movement initiation could run as much through its cortical as through its tegmental outflow.

\section{Motor Programs}

When movement inception occurs is a matter of definition: it could be timed from cortical, muscular or mechanical events. The roles of the cerebellum and the basal ganglia in the planning stage that precedes activity in the motor cortex are not yet clear. Some observations have been made however on involvement of the lateral cerebellum in execution of programmed movements, i.e. those with apparently predetermined parameters. Rapid (ballistic) alternating arm movements between mechanical stops were compared in normal trained monkeys and during dentate cooling (Conrad and Brooks, 1974). The monkeys let the handle touch the mechanical stops only very briefly, so that in the alternation the terms were executed sharply. Unexpected narrowing of the range of movement between trials, by shifting one or both of the mechanical stops closer toward the center, affected only the shortened parts of the traverse. Figure 8A shows that instead of the usual sharp return from the point of impact, the handle was held against the stop for the length of time it would have taken to complete the usual extensions or flexions, suggesting that the durations of the extension-flexion
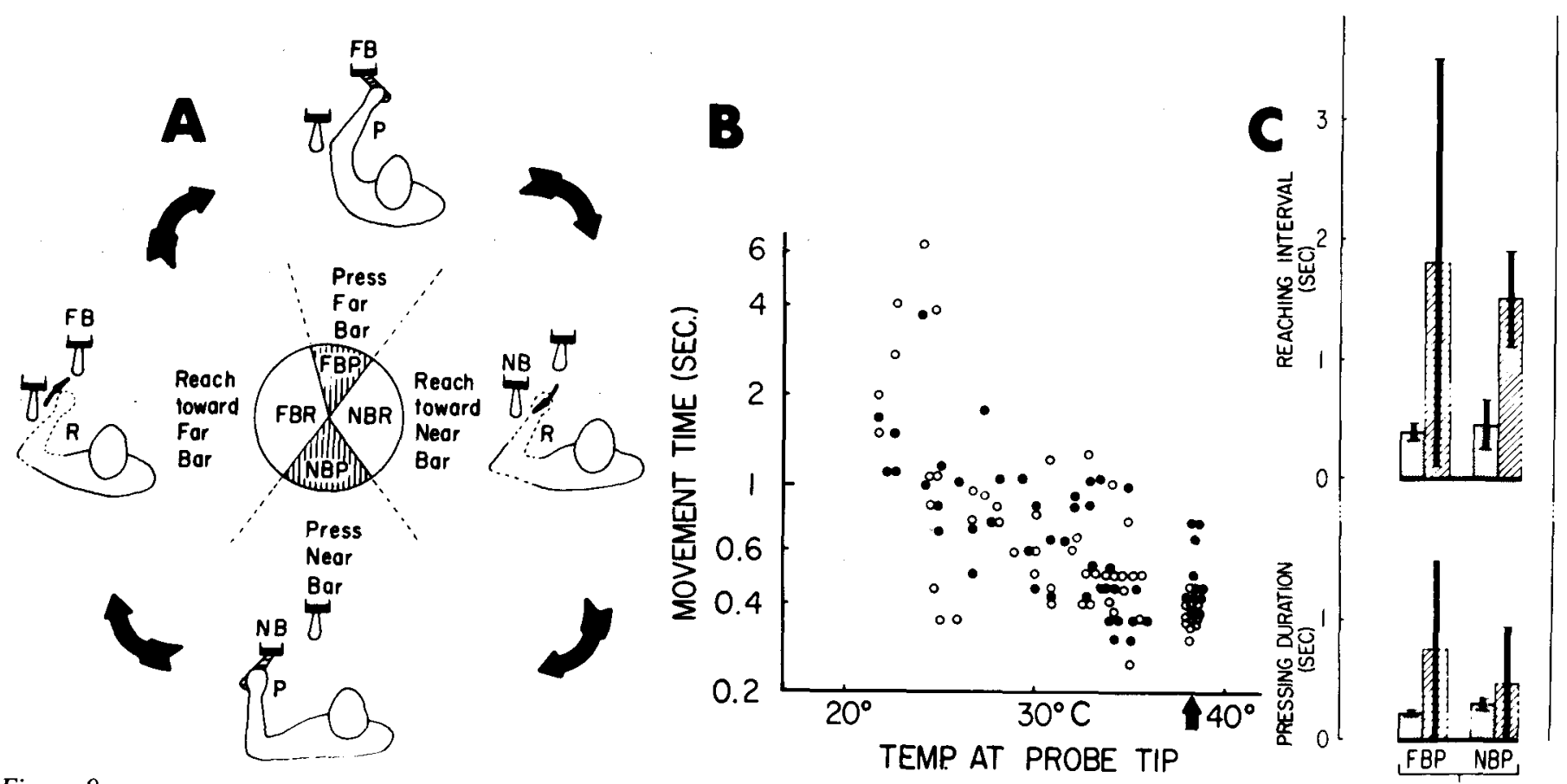

Figure 9-

A: Alternating bar-pressing. Task cycle for arrangement of the near bar (NB) and far bar (FB). Movements are divided into sequential phases of reaching toward the near bar (NBR), pressing the near (NBP), and reaching toward the far bar (FBR). Average relative times for each phase are indicated by the relative widths of sectors in the center circle.

B: Reaching times as a function of temperature. Control at arrow. FBR: filled circles. NBR: open circles.

$\mathrm{C}$ : Effects of cooling ipsilateral dentate nucleus on timing of movements. Ordinates: times in sec. Histograms show averages over 10 consecutive task cycles of reaching times (upper row: FBR, NBR) and pressing times (lower row: FBP, NBP) during control (stippled) and cooling (hatched) periods. Standard deviations are indicated by solid thin bars.

(Modified from Horvath et al., 1970.) 
cycles were "programmed" for the usual $400 \mathrm{msec}$ in this well-learned task.

The most conspicuous effects of dentate cooling on rapid alternations were an increase in the means and dispersion of movement durations and hence a decrease of movement frequency. Figure $8 \mathrm{~B}$ reveals that movements had unchanged velocities or accelerations but that they were prolonged by delayed EMG termination which in turn, delayed initiation of the return movement. The agonist contracted only after the antagonist ceased contracting. Dentate cooling neither changed the reciprocal actions of biceps and triceps, nor the amount, or intensity, of force generated. The timing of muscle action in relation to the termination of normal movements could neither have been a voluntary reaction to the termination, since the latency was much shorter than the usual reaction time, nor could it have been an internal trigger mechanism set off by movement termination, because the EMG often terminated before the arm reached the stop. These rapid alternations, for which the spatial domain was prescribed, therefore must have been programmed for exertion of the correct amount of force for the correct length of time. According to Holmes (1917) hypermetria is "always associated with a delay in initiating or completing the relaxation of a counteracting muscle." Holmes considered hypermetria basically to be of the same derivation as the rebound phenomenon which describes the inability of cerebellar patients to arrest an isometrically contracting muscle after the sudden release of a restraining force. It is caused by delayed termination of agonistic muscular activity, and thus of a delayed (or missing) initiation of the antagonist. Adiadochokinesis is the inability to perform rapid alternate movements. Holmes noted that "the slowness is due chiefly to delay at the turn and not to time lost in the movements themselves, for there is rarely much difference in the rate of these and of those of the normal limb."

Identification of less precise movements as being preprogrammed is more difficult be-

\section{COOLING GLOBUS PALLIDUS}
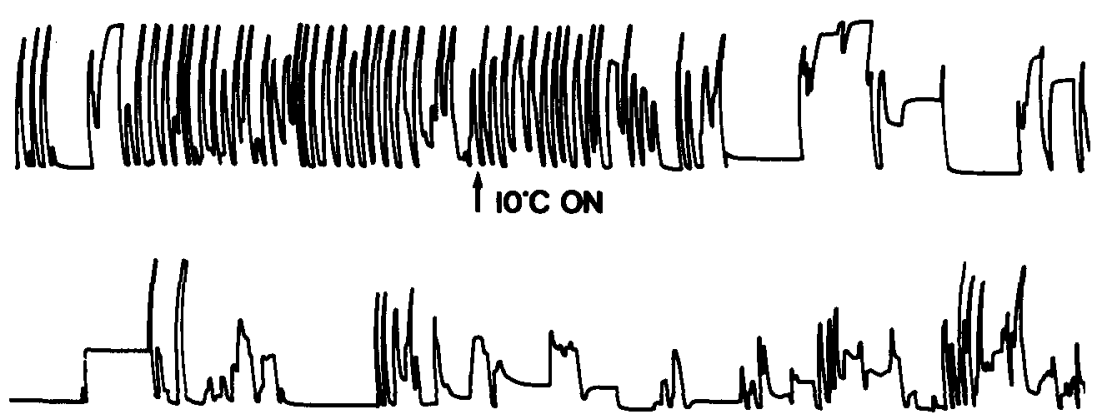

I min. later

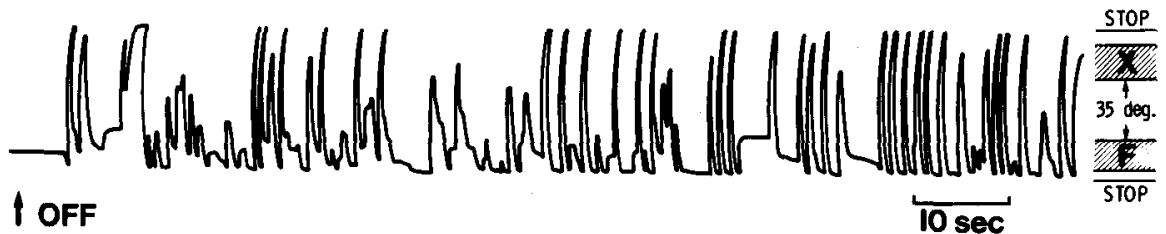

Figure 10-

A: Effects on alternating elbow flexions and extensions of cooling contralateral globus pallidus to $10^{\circ} \mathrm{C}$ probe ref. temp. (at "start"' arrow).

B: 2 min later.

C: Return towards normal after stopping cooling (arrow). All records of individual trials.

(From Hore, Meyer-Lohmann and Brooks, unpublished.) cause errors of execution are harder to discern (cf. Brooks, 1974). We made attempts with self-paced elbow movements, that the monkeys had to terminate in learned target zones without the aid of mechanical stops (Kozlovskaya et al., 1974). The animals learned the target positions through long practice, aided by auditory and visual target cues. Some evidence for programming of durations or amplitudes was obtained for some relatively fast movements by unexpected withdrawal of target cues or by their unexpected insertion in unusual parts of the trajectory. Under those circumstances the movements ran their usual course, indicating independence of the target cues. This was not so for slower movements that consistently overshot when target cues were omitted, revealing their dependence on audio-visual target cues, and suggesting that they were programmed less securely than faster movements (Kozlovskaya et al., 1974). Cooling of the dentate nucleus, but not the interpositus (IP), could render both kinds of movements dysmetric, but the monkeys made increased use of the slower kind (identified by a $3 \mathrm{~Hz}$ tremor in the acceleration trace) for which they learned to avoid dysmetria. In addition, dentate but not IP cooling made the movement alternations less regular (Fig. 11, and Brooks et al., 1973; Uno et al., 1973). These results with slow movements argue against Kornhuber's (1974) suggestion that the cerebellar cortex is concerned only with the timing of fast (saccadic) movements. His other suggestion, that the nuclei are only concerned with holding a limb steady, as opposed to moving it, seems to be counterindicated by the exaggerated tremor during movement as well as holding, when the dentate is cooled (cf. Figs. 11 and 12, and Brooks et al., 1973; MeyerLohmann et al., 1975).

One more aspect of Holmes' (1917) descriptions of cerebellar deficit is appropriate here: that of decomposition of "complex" reaching movements. We confirmed that dentate cooling can produce errors of direction, regularity and coordina- 
tion when the monkey has to make reaching movements (Horvath et al., 1970). Figure 9A illustrates the barpressing task. Figure 9B plots the dependence of the effects on dentate temperature. Figure 9C graphs the great prolongation of reaching times during cooling, particularly away from the body, marked by irregular sequences with tremulous searching movements akin to intention tremor.

Recently we have begun a study of the basal ganglia by applying the cooling method to an important output nucleus: the globus pallidus (Hore et al., 1975). A very different result was obtained compared to cooling cerebellar output nuclei. EMG activity in the biceps and triceps increased, co-contractions appeared, and the limb contralateral to the cooled structure tended to assume a flexed posture. The most dramatic change however was the breakdown of the alternating movements that were made without visual guidance, such that they became irregular and greatly reduced in amplitude. This can be seen in the recordings of Figure 10 that are typical of all 3 animals investigated so far. However, even during cooling to $5^{\circ}$ $\mathrm{C}$ for over $10 \mathrm{~min}$, these same animals were still able to reach accurately under visual control for pieces of food held in front of them. It appears that cooling the globus pallidus causes dysfunctions in the absence of visual information. There seem to be striking similarities to the clinical picture as described by Martin (1967), but the physiological details remain to be worked out.

\section{Control}

The anatomical connections outlined in Figures 1 and 3 lead to the expectation expressed in Figure 2 that cooling the dentate would mostly affect planning and initiation of movements, while cooling the interpositus would mostly interfere with execution. Although cooling cannot be restricted entirely to one nucleus or the other (Fig. 6), one might at least expect a preponderance of appropriate effects. These expectations were only partly fulfilled. As recounted in the previous section, movement initiation was indeed de- layed not only by cooling the dentate, but also the interpositus. Furthermore, errors of range, rate, and force were more prominent with cooling the dentate (Brooks et al., 1973) than the interpositus (Uno et al., 1973). Well-trained animals learned to compensate for the dentate, as illustrated in Figure 11, but excessive velocities remained, particularly in extensions, although flexions tended to become slow (Meyer-Lohmann et al., 1975). Figure 12 illustrates that point, and in addition demonstrates the continued relation between neural discharge in the motor cortex and the acceleratory changes in the movements. Tremor in the $3 \mathrm{~Hz}$ band became more prominent, supplanting $6 \mathrm{~Hz}$ as the dominant frequency (cf. Brooks et al., 1973, 1974; Cooke and Thomas, 1975, unpublished). In contrast, cooling the $n$. interpositus slowed both extensions and flexions (Fig. 15, and Uno et al., 1973; Vilis, Meyer-Lohmann, Hore and Brooks, 1975, unpublished).

In order to focus the effects of cooling on motor actions that demonstrably depended on peripheral feedback, we injected perturbations at random times into the self-paced movements described so far (Conrad et al., 1974). This was accomplished through a torque-motor mounted beneath the handle shown in Figure 5 . The effects of a brief load pulse opposing an ongoing flexion at time " 0 " are illustrated in Figure 13A taken from Conrad et al., (1975). The EMG indicates that the biceps responded to the stretch twice. The first response occurred with a latency compatible with the spinal stretch reflex, but the second response was too late, and must have traversed a supraspinal route, pre-
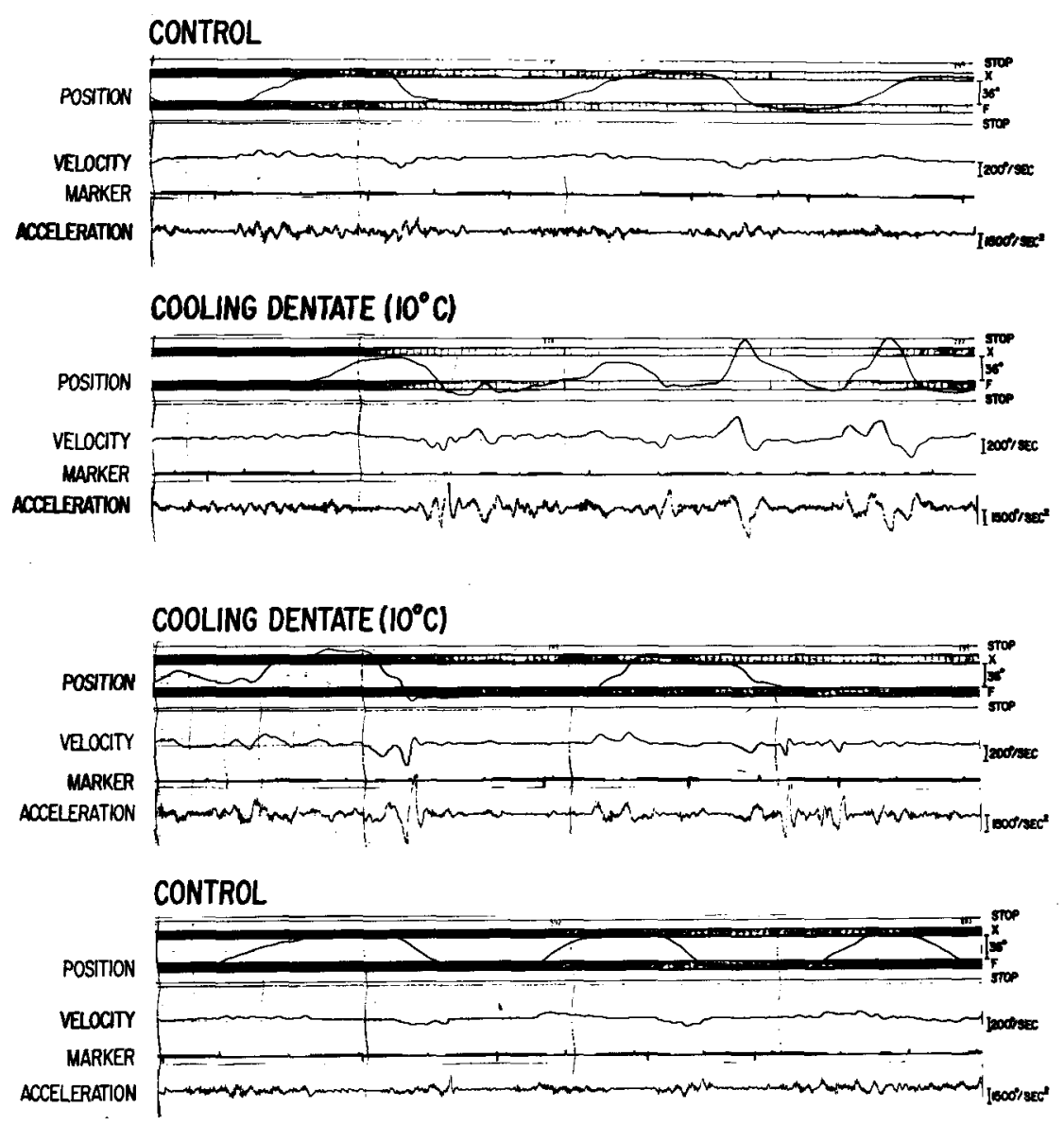

Figure 11-Effects on alternating elbow flexions and extensions of cooling ipsilateral dentate nucleus to $10^{\circ} \mathrm{C}$ probe ref. temp. Two cooling periods were about $10 \mathrm{sec}$ and $2 \mathrm{~min}$ after control. All records of individual trials.

(Modified from Brooks et al., 1973.) 
sumably including the motor cortex. The resulting muscle contractions occurred in time to have generated the acceleration peaks, marked by
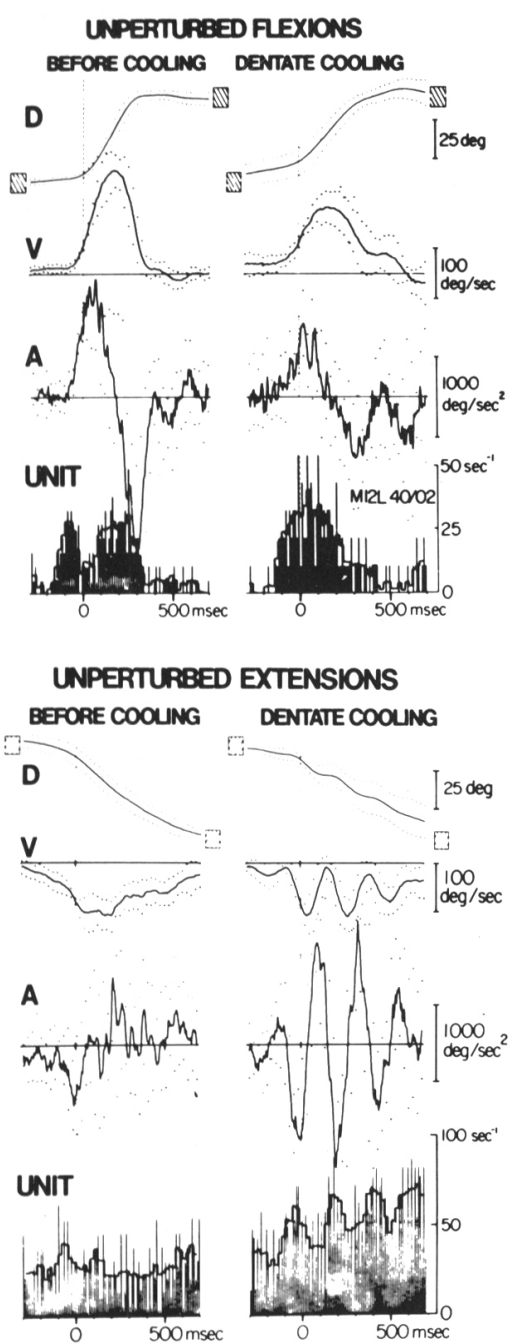

Figure 12-Effects of cooling ipsilateral dentate nucleus on elbow flexions and extensions, as well as precentral unit discharge. Computer generated averages ( \pm SDs) of about 20 records of handle displacement (D), velocity (V), and acceleration (A). $F$ and $X$ targets indicated by hatched boxes; $X$ in downward direction. Dashed vertical lines indicate reference time for computation, based on velocity of 70 $\mathrm{deg} / \mathrm{sec}$. Normalized peristimulus time histograms of unit discharge plotted with $10 \mathrm{msec}$ binwidth for bars and with 20 msec binwidth after two passes of a 10 -point ( $2 \mathrm{msec}$ binwidth) moving average for envelope curve.

(Modified from Meyer-Lohmann et al., 1975.) arrows in trace $\mathrm{A}$, that helped return the limb to its intended path as shown in trace $D$. The lowest trace in Figure 13A shows typical discharge times of a precentral neuron that could have participated in generating the second muscular response, but not necessarily to the exclusion of spinal participation as shown in different ways by Evarts (1975) and by Vilis and Cooke (1975).

Phillips (1968) has pointed out that neurons in the motor cortex presumably respond to mismatch between the intended and the actual movement, since they receive convergent input from motor program instructions as well as peripheral feedback (cf. Fig. 2). We would therefore expect their signal of "error" to correspond to the difference between values of one or several parameters of perturbed and unperturbed movements. In fact, the amplitudes of cortical responses were monoton- ically related to peak velocity or acceleration caused by the perturbation, which is not surprising since it was quite strong. Although correction of the displacement error was almost complete in the time segment illustrated in Figure 13A, subsequent movement oscillations occurred as illustrated in Figure 13B. The arrows in the insets indicate those efferent and afferent events whose timing is plotted in the figure, revealing the similarities to the early cortical response. The late cortical responses were not as stimulus-bound as the early ones: only their timing, but not their amplitudes, were related to the late oscillations of acceleration, marked by arrows in Figure 13B. Again, that is not too surprising since the amplitudes of those oscillations, i.e. tremor, was small; presumably some other, centrally determined factors, governed the amplitudes of late cortical responses. That notwithstanding however, both

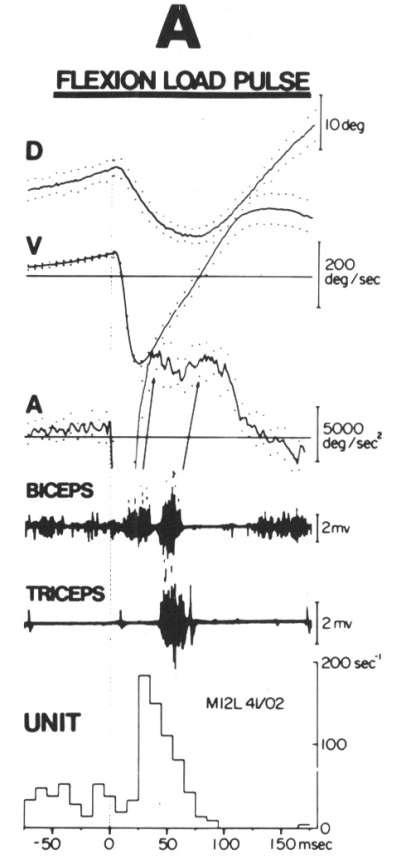

Figure 13-

A: Movement parameters (D, V, A), EMG of biceps and triceps muscles, and early precentral unit response following flexion load pulses in about 20 trials. Arrows point from successive EMG bursts to 1 st and 2 nd acceleration peaks.

B: Latency relations of peaks of late precentral responses to those of accelerations or decelerations. Arrows in upper and lower insets point out "efferent" and "afferent" relations. Regression lines \pm SDs (stippled areas) were calculated from late responses of 18 units.

(Modified from Conrad et al., 1975.) 
early and late precentral responses reflect feedback from the evolving movement, and both may influence spinal motor output.

Since the late precentral responses seemed to be governed partly by central rather than peripheral factors, while the early ones were not, we could expect cooling of the dentate nucleus (as a processor of central information) to have larger effects on late rather than on early responses (cf. Figs. 1-3). This was the case, as illustrated in Figure 14A taken from Meyer-Lohmann et al. (1975). Early precentral responses were unaffected, presumably because their input in response to the strong perturbations largely reached the motor cortex through paths that bypassed the lateral cerebellum. Thus the tightly coupled interaction between the precentral motor cortex and the evolving movement was independent of the dentate function in the early stages of cortical load compensation. The dentate nucleus was involved however, in adjusting intensity and frequency of subsequent late precentral responses and of movement oscillations.

The dominant frequency of the late responses was found to decrease from near $6 \mathrm{~Hz}$ to near $3 \mathrm{~Hz}$, much as had been found for the tremor discernible in acceleration traces of unperturbed movements. The slowing of tremor may be due to prolongation of protagonist muscle action (as had been illustrated for faster movements in Figure 8B) and consequent responses of primary spindles, whose indirect projection to the motor cortex (cf. Wiesendanger, 1973) may go through the sensory cortex and the association cortex before reaching the lateral cerebellum. Tsukahara and Allen (1974) may have had something like that in mind when they drew the interrupted arrow in Figure 2. The motor cortex would thus be deprived of a phasesensitive error signal, and could become more dependent on other input. Dentate cooling would have reduced peripheral feedback and/or central feed-forward control for the late precentral response, by breaking a link between association and motor cortex. In this peripherally

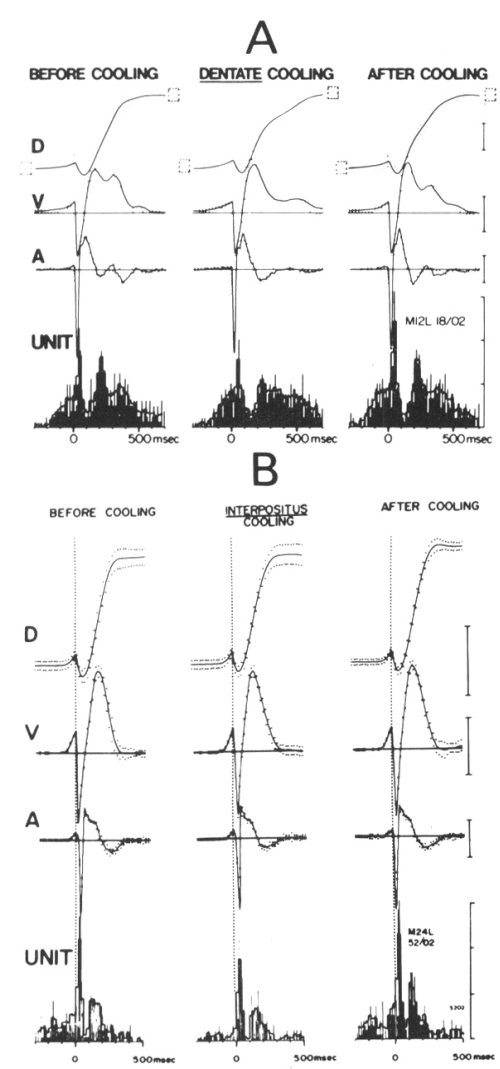

Figure 14-Effects of cooling ipsilateral dentate nucleus (A) and interpositus nucleus (B) on perturbed elbow flexions, as well as on precentral unit discharge. Computer averages and histograms obtained as in Fig. 12. Scales apply to both A and B: Traces D: 25 $\mathrm{deg}, \mathrm{V}: 200 \mathrm{deg} / \mathrm{sec}, \mathrm{A}: 5000 \mathrm{deg} / \mathrm{sec}^{2}$, Unit: $150 \mathrm{sec}^{-1}$.

A: From Meyer-Lohmann et al., 1975.

B: From Vilis, Meyer-Lohmann, Hore and Brooks, 1975, unpublished.

driven event, dentate cooling did not break the efferent coupling between motor cortex and cord: precentral neurons and muscles continued to discharge in common cadence.

By what route did the input for the early cortical response reach the motor cortex? It could have been projected by way of the sensory cortex or through the pars intermedia of the cerebellum and $n$. interpositus (cf. Figs. 2, 3B and 4). The possibility of a trans-cerebellar route to the cortex for primary spindle information had been raised by Phillips (1968) and has since been demonstrated in acute experiments with cats by Murphy et al. $(1974,1975)$.
However, the early precentral response to perturbations was found to be unaffected by cooling the $n$. interpositus in our behavioral situation. Figure 14B presents an example from one animal (Vilis, MeyerLohmann, Hore and Brooks, to be published): the early response to the perturbation was essentially unchanged and was merely riding on a lower level of ongoing neural activity. These results throw doubt on major use of a transcerebellar route in cortical load compensation under our experimental conditions. The roles of various supraspinal loops in follow-up corrections of movements still remain to be clarified.

\section{DISCUSSION}

Stein asked why the M2 response of biceps to perturbation was accompanied by triceps cocontraction. Brooks answered that triceps fired as a spinal stretch reflex in response to its transient relative extension after the pulse-induced peak velocity in the extension direction.

In response to Girvin enquiry whether cooling of the globus pallidus lent evidence in support of Kornhuber's suggestion that the basal ganglia are mostly involved in controls of slow movements, Brooks and Hore replied in the negative. Hore emphasized that three animals had been trained to make movements without visual guidance in a task that therefore depended on proprioceptive information. Breakdown of fast or slow movements therefore seemed to have something to do with that aspect of the task, in analogy to Purdon Martin's suggestion. Jasper's question as to the results of cooling both the globus pallidus and the dentate nucleus was answered by Brooks to the effect that cooling both nuclei together worsened the ability to hold steady, but did not lead to a breakdown of movement.

\section{ACKNOWLEDGEMENTS}

This review owes very much to the many discussions with all of my associates, whose names appear in the references. I am particularly indebted to the recent contributions of Doctors Justus Meyer-Lohman, Bastian Con$\mathrm{rad}$, Mario Wiesendanger, Jon Hore and Tutis Vilis.

I am grateful to the Editors of Brain Res., Int. J. Neurol., J. Neurophysiol., Phil. Trans. Roy. Soc. Lond., Physiol. Rev., and Springer-Verlag for permission to reproduce Figures.

\section{REFERENCES}

ALLEN, G. I., and TSUKAHARA, N. (1974). Cerebro-cerebellar communication systems. Physiol. Rev., 54, 957-1006.

ANDERSEN, P., GJERSTAND, L., and PASZTOR, E. (1972). Effect of cooling on 
synaptic transmission through the cuneate nucleus. Acta physiol. scand., 84, 433-447.

BENITA, M., and CONDE, H. (1972). Effects of local cooling upon conduction and synaptic transmission. Brain Res., 36, 133-151.

BOWSHER, D. (1965). The anatomophysiological basis of somatosensory discrimination, Int. Rev. Neurobiol., 8, 35-75.

BROBECK, J. R. (1974). The Second Stevenson Lecture. Regulations and Integrations. Can. J. Physiol. Pharmacol., 52, 769-779.

BRODAL, A. (1969). Neurological Anatomy in Relation to Clinical Medicine. Oxford University Press, New York.

BROOKS, V. B., and STONEY, S. D. (1971). Motor mechanisms: the role of the pyramidal system in motor control. Ann. Rev. Physiol., 33, 337-392.

BROOKS, V. B., KOZLOVSKAYA, I. B. ATKIN, A., HORVATH, F. E., and UNO, M. (1973). Effects of cooling dentate nucleus on tracking-task performance in monkeys. J. Neurophysiol., 36, 974-995.

BROOKS, V. B. (1974). Some examples of preprogrammed and feedback-guided movements. Brain Res., 71, 299-308.

BROOKS, V. B., COOKE, J. D., and THOMAS, J. S. (1974). The continuity of movements. In: Control of Posture and Locomotion. R. B. Stein, K. G. Pearson, R. S. Smith and J. B. Redford, eds. New York: Plenum Press, pp. 257-272.

BUTZ, P., KAUFMANN, W., and WIESENDANGER, M. (1970). Analyse einer raschen Willkurbewegung bei Parkinsonpatienten vor und nach stereotaktischem Eingriff am Thalamus. Z. Neurol., $198,105-119$.

CAMIS, M. (1923). Recherches sur le mecanisme central des mouvements de deambulation. Arch int. de physiol., 20, 340-370.

CARPENTER, M. B. (1973). Comparisons of the efferent projections of the globus pallidus and substantia nigra in the monkey. In: Efferent Organization and the Integration of Behavior. J. D. Maser, ed. New York: Academic Press, pp. 137-174.

CONRAD, B., and BROOKS, V. B. (1974). Effects of dentate cooling on rapid alternating arm movements. J. Neurophysiol., 37, 792-804.

CONRAD, B., MATSUNAMI, K. MEYER-LOHMANN, J., WIESEN DANGER, $M$, and BROOKS, V. B (1974). Cortical load compensation during voluntary elbow movements. Brain Res. $71,507-514$

CONRAD, B., MEYER-LOHMANN, J., MATSUNAMI, K., and BROOKS, V. B. (1975). Precentral unit activity following torque pulse injections into elbow movements. Brain Res. 86. In press.

COOPER, I. S. (1969). Involuntary Movement Disorders. Harper and Row, New York.

DAHLSTROM, A., and FUXE, K. (1964). Evidence for the existence of monoamine- containing neurons in the central nervous system. I. Demonstration of monoamines in the cell bodies of the brain stem neurons. Acta physiol. scand., Supplement 232, 62, $1-5$.

DELONG, M. R., and STRICK, P. L. (1974). Relation of basal ganglia, cerebellum, and motor cortex units to ramp and ballistic limb movements. Brain Res., 71, 327-335.

DENNY-BROWN, D. (1962). The Basal Ganglia. Oxford University Press, London.

DOW, R. S., and MORUZZI, G. (1958). The Physiology and Pathology of the Cerebellum. University of Minnesota Press, Minneapolis.

ECCLES, J. C. (1969). The dynamic loop hypothesis of movement control. In: Information Processing in the Nervous System. K. N. Leibovic, ed. Heidelberg: Springer Verlag, pp. 245-269.

ECCLES, J. C. (1972). The First Stevenson Lecture. The role of the brain in movement and skill. (Unpublished.)

ECCLES, J. C. (1973). Review lecture: The cerebellum as a computer; patterns in space and time. J. Physiol., 229, 1-32.

EVARTS, E. V., and THACH, W. T. (1969). Motor mechanism of the CNS: cerebrocerebellar interrelations. Ann. Rev. Physiol., 31, 451-498.

EVARTS, E. V. (1975). The Third Stevenson Lecture. Changing concepts of central control of movement. Can. J. Physiol. Pharmacol., 53, 191-201.

GARVER, D. L., and SLADEK, J. R. (1975). Monoamine distribution in primate brain. $\mathrm{J}$. comp. Neurol., 159, 289-304

GILMAN, S. (1972). The nature of cerebellar dyssynergia. In: Modern Trends in Neurology. D. Williams, ed. London: Butterworths, 5, pp. 60-79.

GILMAN, S., and EBEL, H. C. (1970) Fusimotor neuron responses to natural stimuli as a function of prestimulus fusimotor activity in decerebellate cats. Brain Res., 21, 367-384.

GRANIT, R. (1970). The Basis of Motor Control. Academic Press, New York.

GRANIT, R., HOLMGREN, B., and MERTON, P. A. (1955). The two routes for excitation of muscle and their subservience to the cerebellum. J. Physiol., 130, 213-224.

HOLMES, G. (1917). The symptoms of acute cerebellar injuries due to gunshot injuries. Brain, 40, 461-535.

HORE, J., MEYER-LOHMANN, J., and BROOKS, V. B. (1975). Cerebellar influence on simple reaction time in primates. Abstr. 5th Ann. Meeting, Soc. Neuroscience.

HORE, J., MEYER-LOHMANN, J., and BROOKS, V. B, (1975). Effects of cooling globus pallidus on monkey arm movements. Canada Physiology, 6, 30.

HORVATH, F., ATKIN, A., KOZLOVSKAYA, I., FULLER, D. R. G., and BROOKS, V. B. (1970). Effects of cooling the dentate nucleus on alternating barpressing performance in monkey. Int. J. Neurol., 7, 252-270.
HOUK, J. C. (1972). On the significance of various command signals during voluntary movement. Brain Res., 40, 49-58.

ITO, M. (1970). Neurophysiological aspects of the cerebellar motor control system. Int. J. Neurol., 7, 162-176.

JASPER, H. H., SHACTER, D. G., and MONPLAISIR, J. (1970). The effect of local cooling upon spontaneous and evoked electrical activity of cerebral cortex. Can J. Physiol. Pharmacol., 48, 640-652.

KEMP, J. M., and POWELL, J. P. S. (1971). The connexions of the striatum and globus pallidus: synthesis and speculation. Phil. Trans. Roy. Soc. Lond. B., 262, 441-457.

KORNHUBER, H. H. (1974). Cerebral cortex, cerebellum, and basal ganglia: an introduction to their motor functions. In: The Neurosciences, Third Study Program. F. O. Schmitt and F. G. Worden, eds. Cambridge, Mass.: MIT Press, pp. 267-280.

KOZLOVSKAYA, I. B., ATKIN, A., HORVATH, F. E., THOMAS, J. S., and BROOKS, V. B. (1974). Preprogrammed and feedback-guided movements of monkeys. Behav. Biol., 12, 243-248.

LAWRENCE, D. G., and KUYPERS, H. G. J. M. (1968). The functional organization of the motor system in the monkey. I. The effects of bilateral pyramidal lesions. Brain, 91, Part I, 1-14.

LAWRENCE, D. G., and KUYPERS, H. G. J. M. (1968). The functional organization of the motor system in the monkey. II. The effects of lesions of the descending brainstem pathways. Brain, 91, Part I, 15-36.

LIU, C. N., and CHAMBERS, W. W. (1971). A study of cerebellar dyskinesia in the bilaterally deafferented forelimbs of the monkey. Acta Neurol. Exptl., 31, 263-289.

MARTIN, J. P. (1967). The Basal Ganglia and Posture. Pitman Medical, London.

MEYER-LOHMANN, J., CONRAD, B., MATSUNAMI, K., and BROOKS, V. B. (1975). Effects of dentate cooling on percentral unit activity following torque pulse injections into elbow movements. Brain Res. 86. In Press.

MILLER, A., MEYER-LOHMANN, J., HORE, J., and BROOKS, V. B. (1975). Relation between cerebellar nuclei and simple reaction time. Proc. Can. Fed. Biol. Soc., $18,148$.

MURPHY, J. T., WONG, Y. C., and KWAN, H. C. (1974). Distributed feedback systems for muscle control. Brain Res., 71, 495-506.

MURPHY, J. T., WONG, Y. C., and KWAN, H. C. (1975). Afferent-efferent linkages in motor cortex for single forelimb muscles. J. Neurophysiol., In Press.

NICHOLS, T. R., and HOUK, J. C. (1973). Reflex compensation for variations in the mechanical properties of a muscle. Science, $181,182-184$.

OSCARSSON, O. (1973). Functional organization of spinocerebellar paths. In: Handbook of Sensory Physiology, Vol. II, Somatosensory System. A. Iggo, ed. Heidelberg: Springer-Verlag, pp. 339-380. 
PANDYA, D. N., and KUYPERS, H. G. J. M. (1969). Cortico-cortical connections in the rhesus monkey. Brain Res., 13, 13-36.

PHILLIPS, C. G. (1969). Motor apparatus of the baboon's hand. The Ferrier Lecture, 1968. Proc. Roy. Soc. B., 173, 141-174.

POIRIER, L. J., and SOURKES, T. L. (1965). Influence of the substantia nigra on the catecholamine content of the striatum. Brain, 88, 181-192.

POWELL, T. P. S., and COWAN, W. M. (1956). A study of the thalamo-striate relations in the monkey. Brain, 79, 364-390.

PURPURA, D. P. (1972). Intracellular studies of synaptic organizations in the mammalian brain. In: Structure and Function of Synapses. G. D. Pappas and D. P. Purpura, eds. New York: Raven Press, pp. 257-302.

SCHMIDT, E. M., JOST, R. G., and DAVIS, K. K. (1975). Re-examination of the force relationship of cortical cell discharge patterns with conditioned wrist movements. Brain Res., 83, 213-223.
STEIN, R. B. (1974). Peripheral control of movement. Physiol. Rev., 54, 215-243.

THACH, W. T. (1975). Timing of activity in cerebellar dentate nucleus and cerebral motor cortex during prompt volitional movement. Brain Res., 88, 233-241.

TRENDELENBURG, W. (1910). Untersuchungen über reizlose vorübergehende Ausschaltung am Zentralnervensystem. I. Vorläufiger Bericht. Pflügers Arch. ges. Physiol., 133, 305-312.

TRENDELENBURG，W. (1910). Untersuchungen über reizlose vorübergehende Ausschaltung am Zentralnervensystem. II. Zur Lehre von den bulbären und spinalen Atmungs und Gefasszentren. Pflügers Arch. ges. Physiol., 135, 469-505.

TRENDELENBURG, W. (1910). Der Einfluss der hoheren Hirnteile auf die Reflextätigkeit des rückenmarks. Pflügers Arch. ges. Physiol., 136, 429-442.

TRENDELENBURG, W. (1911). Untersuchungen über reizlose vorübergehende
Ausschaltung am Zentralnervensystem. III. Die Extremitätenregion der Grosshirnrinde. Pflügers Arch. ges. Physiol., 137, 515-544.

UNGERSTEDT, U. (1971). Stereotaxic mapping of the monoamine pathways in the rat brain. Acta physiol. scand., Supplement $367,1-48$.

UNO, M., KOZLOVSKAYA, I. B., and BROOKS, V. B. (1973). Effects of cooling interposed nuclei on tracking task performance in monkeys. J. Neurophysiol., 36, 996-1003.

VILIS, T., and COOKE, J. D. (1975). Modulation of the functional stretch reflex by segmental reflex pathway. Proc. Can. Fed. Biol. Soc., 18, 148.

VILIS, T., MEYER-LOHMANN, J., HORE, J., and BROOKS, V. B. (1975). Effects of cooling the interposed nuclei on perturbed movements and related precentral unit activity. (In preparation.) 